\title{
Evaluation of health, nutrition and food security programmes in a complex emergency: the case of Congo as an example of a chronic post-conflict situation
}

\author{
Laura Rossi ${ }^{1, *}$, Thomas Hoerz ${ }^{2}$, Veronique Thouvenot ${ }^{3}$, Gianni Pastore ${ }^{1}$ and \\ Markus Michael ${ }^{4}$ \\ ${ }^{1}$ Human Nutrition Unit, National Institute for Research on Food and Nutrition, via Ardeatina 546, 00178 Rome, Italy: \\ ${ }^{2}$ Consultant for Food Security and Agricultural Development, Rome, Italy: ${ }^{3}$ European Centre of Humanitarian Health, \\ Lyon, France: ${ }^{4}$ Consultant for Public Health and Humanitarian Aid, San Paulo, Brazil
}

Submitted 31 August 2005: Accepted 15 December 2005

\begin{abstract}
Objective: To describe the case of Congo as an example of the assessment and appropriateness of donor operational and sectoral strategies in a complex emergency. Design and setting: The paper reports the findings of an external evaluation of operations financed by the European Commission Humanitarian Office in the Democratic Republic of Congo (DRC).

Results: The Congolese health system is suffering from severe deterioration. What is functioning in the public health context is donor-dependent with high costs and limited coverage. Despite a relatively favourable agro-climatic situation, food shortage and famine severely affect the nutritional status of large population groups. In this context, humanitarian programmes have generally improved access to health care and the nutritional status of beneficiaries. The reduction of malnutrition in project areas is often demonstrated even though the context did not permit consolidation of these results. Malnutrition continues to claim a massive cost of lives owing to the effect of widespread food insecurity that follows a circular cause-andeffect pattern of very low food production and extreme poverty.

Conclusions: The current context in DRC does not correspond yet to 'post-crisis': neither at population level with regard to indicators of poverty, malnutrition, disease and death, nor at institutional level, with regard to state support to institutions. In these situations, the international community is often called upon to replace the state as service provider. Integrated humanitarian actions should be the future of relief projects in DRC. Health, nutrition and food security components should be considered a standard public health intervention strategy representing the most sensible approach to address the needs of the affected population.
\end{abstract}

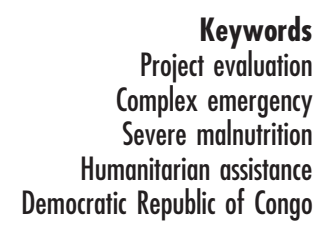

Keywords Project evaluation Complex emergency Severe malnutrition Democratic Republic of Congo
Complex and violent conflicts have raged across the Democratic Republic of Congo (DRC, formerly Zaire) in the last decade. Despite the recent slow peace process, DRC is still in a very critical and precarious situation with persistent patterns of violence and insecurity. It features some of the world's worst mortality rates, which in 2002 were reported to be twice as high as sub-Saharan averages ${ }^{1}$. Food shortage and famine affect particularly vulnerable groups of the population. The situation on the ground, especially the widespread extreme poverty, is unlikely to improve significantly in the near future. This is in contrast to what might be expected through an analysis of the agro-climatic and environmental features of the country. In fact, DRC is characterised by an extended agricultural season which, in different areas, ranges between two-thirds of the year and the entire year. This favourable environment could allow at least two harvests of cereals per annum. Moreover, the adequate soil moisture during practically whole year should enable cultivation of vegetables and crops that elsewhere need irrigation. Very severe food shortage should not be expected under these conditions, and the population should not have to, adopt peculiar strategies to cope with harsh seasonality in food availability. However, the Congolese nutritional status is precarious and definitely worse than that found in other areas in Africa which have a less favourable agro-climatic pattern. War and continuous armed conflicts are the main causes of this current misery. Even the extreme poverty has earlier roots than the recent fighting: the pre-war history of Zaire is a textbook example of state failure and collapse ${ }^{2}$.

The European Commission Humanitarian Office (ECHO) is the largest donor of humanitarian aid in DRC, with the allocation of $€ 122.1$ million between 2002 
and $2004^{3}$. In 2004, DRC topped the ECHO list of worldwide vulnerability ranking, with the highest Global Index for Humanitarian Needs Assessment and preceding Afghanistan and $\mathrm{Iraq}^{4}$. In 2004, ECHO concentrated activities (health, nutrition and food security) in the Eastern 'red zone'- grossly corresponding to the Greater Kivu and Ituri areas, still most affected by conflict - and in the 'blue zone' along the former front line, which gained a certain degree of minimal contextual stability (Fig. 1).

The present paper reports the findings and conclusions of an external evaluation of ECHO-financed operations since 2002, focusing particularly on the projects implemented in 2003 and 2004. The objective of the work is to describe the case of DRC as an example of the assessment and appropriateness of donor operational and sectoral strategies in a complex emergency, in order to define a coherent and viable transition plan.

\section{Evaluation procedure}

The team of evaluators consisted of four members: a public health physician (team leader), a health economist, a nutritionist and an agronomist. After three days of briefing and desk study in Brussels, the group spent four weeks (July-August 2004) in the field, travelling in two separate teams, for the evaluation of health projects and nutrition and food security programmes. After some initial contacts in Kinshasa with international humanitarian representatives and government authorities, the time in the field was used visiting a representative sample of implementing partners (IPs) and their projects in the local context. Mortality and morbidity statistics were collected from hospitals and health centres, while nutrition and food security information was gathered from databases provided by different IPs. Semi-structured individual and group interviews were held with key informants at the level of partners, relevant Ministries, United Nations agencies, local authorities and community leaders, as well as randomly selected members of the target population groups. Interviews were often coupled with direct observation during visits to health services, feeding centres and agricultural projects. Triangulation was employed throughout the process of data gathering and analysis, comparing interview material, observations and documents from different sources. Nutritional programmes were evaluated according to internationally accepted Sphere standards ${ }^{5}$.

\section{Main findings of the evaluation}

\section{Health}

The experts visited 12 out of 19 health projects. Data from hospitals showed that, in DRC, malaria is the main contributor to the mortality rate and is responsible for about half of childhood deaths $(52 \%$ in 2003); acute respiratory tract infections, diarrhoea

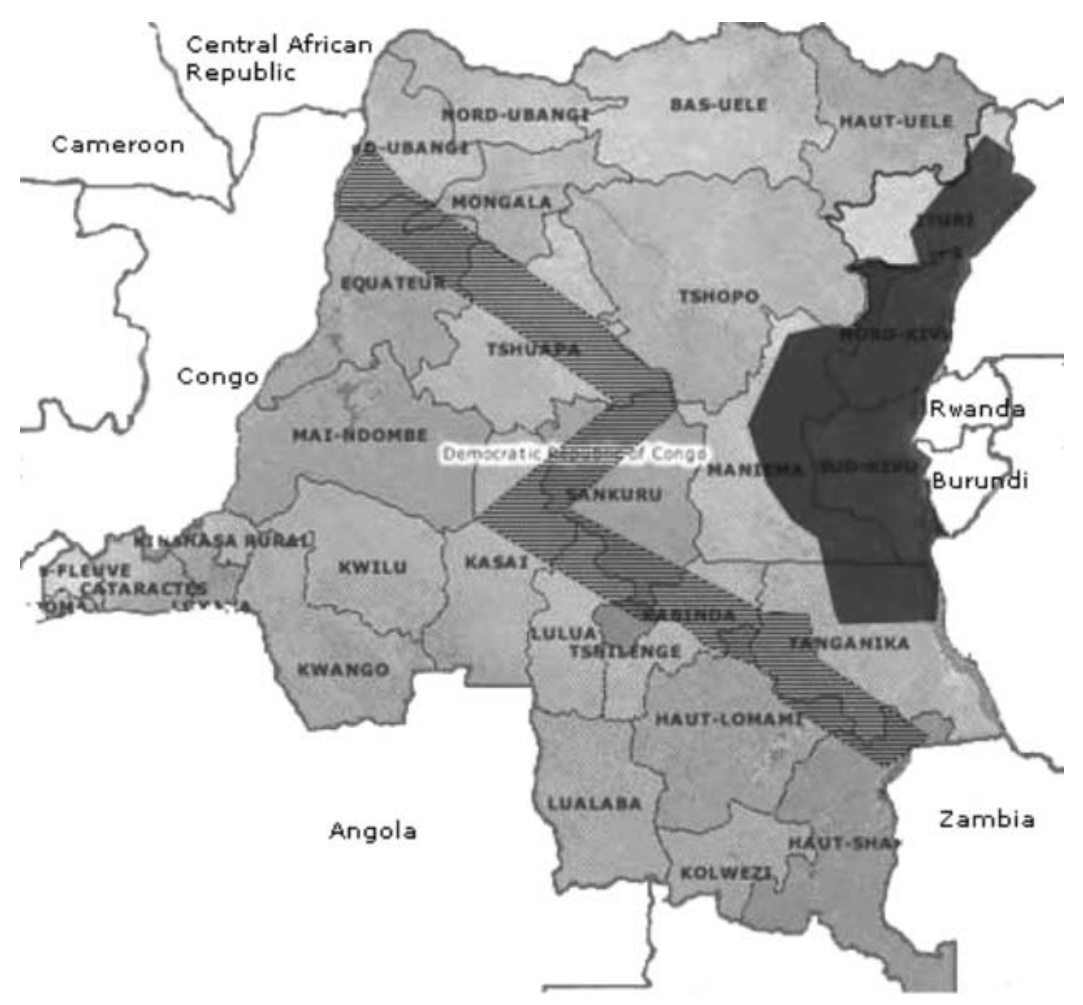

Fig. 1 Map of Democratic Republic of Congo, showing geographical priorities of the European Commission Humanitarian Office 4 . , unstable regions still suffering from conflict or emerging from recent conflict - Ituri and Grand Kivu ('red zone'); 仼, regions where intense fighting took place between 1998 and 2001, and which began to stabilise in 2002 - Équateur, Kasaï and Katanga ('blue zone') 
and measles-associated diseases are other important causes. Among the diseases that regularly cause epidemics are cholera, meningitis, bloody diarrhoea and measles. Immunisation coverage for measles is reported to be lower than $40 \%$ countrywide and was just over $50 \%$ in the health zones visited. AIDS prevalence is estimated to be around 5\%, still lower than in most neighbouring countries. The evaluators found means of $8 \%$ in samples of blood donors (clinically screened) and 3\% in victims of sexual- and gender-based violence. The health system in DRC is suffering from complete deterioration owing to long-standing pre-war negligence and the effects of continuous recent armed conflicts. The system of basically full cost recovery has produced a high rate of economic exclusion. The generally impoverished population is still not able to pay more than nominal fees and the cost of assistance in unsubsidised structures is unaffordable for the population. The evaluators found a price for Caesarean section ranging between \$US 40 and 150 in health structures not supported by international organisations. Health care is mainly provided outside the regular governmental health system, through self-medication or traditional healers. What is functioning of the Congolese health system remains donor-dependent, either from development or humanitarian funds. Excess morbidity and mortality are in large part attributable to insufficient access to health care. The best indicator for access to health care is the user rate (new consultations per person per year), found to be incomparably higher in health services supported by a partner than in those that did not receive support. In Equator (north-west) for example, the average user rate of supported health centres is $1.47,10$ times more than in unsupported health centres (0.145). In Katanga (south) the disproportion is a little bit less, with a user rate of 0.38 for supported health centres compared with 0.059 for unsupported ones. The amount of money budgeted per health service is considered an indicator of efficiency. For similar primary health-care projects, partners working in 'emergency mode' and for short-term activities were found to spend significantly more (on average \$US 410 per health service per year) than organisations with development attitude (average of \$US 49 per health service per year).

\section{Nutrition and food security}

In eastern regions ('red zone', Fig. 1), seven out of 14 nutrition/food security projects were visited. The nutritional approach in Congo is the classical emergency programme with therapeutic feeding centres (TFCs), functioning in local hospitals and admitting very severely malnourished subjects, and supplementary feeding centres (SFCs), established to correct moderate wasting. Admission criteria strictly follow the National Nutritional Protocol $^{6}$, set up in accordance with international guidelines ${ }^{7}$ and adapted to the local conditions. Performance of nutritional centres (NCs) was found to be generally good, in some cases excellent, with well-trained staff and key indicators under the Sphere minimum cut-off points (Table 1). Food stock disruption and security constraints were the main reasons reported by IPs to explain the case of not optimal performance, actually most frequently registered in SFCs. In fact, NC performance was highly dependent on the efficiency of specialised agencies (mainly the United Nations World Food Programme) in guaranteeing the appropriate coverage of food distribution. The family ration, regulated by the national protocol, was highly affected by food availability: the quantity of corn-soy blend, for example, ranged from 60 to 250 grams per day according to the ability of the partners to compensate for food shortage. Absence of protective family rations was reported, either due to partners' decision or food availability constraints. Admission rate of beneficiaries in NCs was constant or even increasing in the period examined. In the visited sites, an average increase of $30 \%$ in admissions was found in the first six months of 2004. A similar increasing level (29\%) was reported in 2003. It should be pointed out that NC admission rate is only partially related to the prevalence of malnutrition in the areas. According to IPs, the presence of patients in NCs is influenced by security, possibility of access and seasonality. The age breakdown of

Table 1 Sphere key indicators for the performance of nutritional centres in different geographical sites. Bold font indicates values exceeding the Sphere cut-off points ${ }^{5}$

\begin{tabular}{|c|c|c|c|c|c|c|c|c|c|c|}
\hline & \multirow{2}{*}{\multicolumn{2}{|c|}{$\begin{array}{l}\text { International } \\
\text { standard }\end{array}$}} & \multicolumn{2}{|c|}{ Bunia } & \multicolumn{2}{|c|}{ Walungu } & \multicolumn{2}{|c|}{ Shabunda } & \multicolumn{2}{|c|}{$\begin{array}{l}\text { Rwanguba/ } \\
\text { Oicha }\end{array}$} \\
\hline & & & I seme & r 2004 & I seme & r 2004 & & & Aug 2 & $3-F e b$ \\
\hline & TFCs & SFCs & TFCs & SFCs & TFCs & SFCs & TFCs & SFCs & TFCs & SFCs \\
\hline Discharge rate (\%) & $>75$ & $>80$ & 82.5 & 68.4 & 85.3 & 75.2 & 90 & 80.3 & 91.9 & 88.8 \\
\hline Mortality rate (\%) & $<10$ & $<3$ & 4.2 & 1.4 & 3.1 & & 2.0 & 1.2 & 0.8 & 0.2 \\
\hline Default rate $(\%)$ & $<15$ & $<15$ & 1.5 & 19.2 & 6.1 & 6.2 & 3.2 & 8.0 & 0.5 & 8.5 \\
\hline Length of stay (day) & $<30$ & $<90$ & 25.4 & 63.8 & 32.0 & 80.0 & - & - & 24.0 & 63.5 \\
\hline Weight gain $\left(\mathrm{g} \mathrm{kg}^{-1}\right.$ day $\left.^{-1}\right)$ & $>8$ & $>2$ & 12.4 & 2.7 & 9.9 & 2.1 & - & - & 12.1 & 2.5 \\
\hline
\end{tabular}

TFCs - therapeutic feeding centres; SFCs - supplementary feeding centres. 
malnourished in NCs showed that children under 5 years old represent the majority of beneficiaries, followed by older children (6-18 years) and women of childbearing age. Adults are generally less represented. In Bunia (northeast), in the first semester of 2004 , the proportion of adults was 6\% (TFCs) and 3\% (SFCs); in Walungu (south west) area in the period of January-March 2004, the proportion of adults was 10\% (TFCs) and 12\% (SFCs); while in the areas covered by other IPs operating in the south-west region the figures were higher, with 43\% (TFCs) and 32\% (SFCs) in 2003 and 37\% (SFCs) in 2004.

The most reliable nutritional indicator in the context of famine and emergency ${ }^{7}$ is the prevalence of acute malnutrition (or wasting), defined as weight-for-height $Z$-score (WHZ) below -2, i.e. below two standard deviations of the reference value, calculated using the National Center for Health Statistics reference ${ }^{8}$. The impact of NCs was demonstrated by the reduction of the prevalence of global wasting (WHZ $<-2$ ) and its severe form (WHZ $<-3$, i.e. below three standard deviations of the reference value) in the areas covered by nutritional programmes (Fig. 2). Despite these good results, malnutrition in DRC still continues to claim a massive cost of lives owing to widespread food insecurity. A tentative conceptual framework of the causes and relationship between poverty, agricultural production and aggravating factors in DRC is modelled in Fig. 3. Food insecurity in DRC follows a circular cause-and-effect pattern of very low and shrinking food production levels and extreme and rising poverty. The decade-long downward trend of this spiral results from the effects of mismanagement, war and continuing insecurity, and lack of geographical access to land and markets. Within this context, all visited food security projects were run fairly effectively and efficiently, and the small part of the population which has access to the programmes benefits from them. Some of the modules already have a strong developmental character, which seems very appropriate for the chronic emergency situation in which the skills to do emergency work have to be combined with developmental tools. Food security interventions are normally attached to NCs; demonstration gardens are generally well maintained and regularly utilised, but multiplication of their effects by creating additional contact gardens close to the beneficiaries' homes was an uncommon practice.

\section{Discussion and conclusions}

The current context in DRC does not yet correspond to 'post-crisis': neither at population level with regard to indicators of poverty, malnutrition, disease and death, nor at institutional level with regard to state support to vital institutions and infrastructure. In this chronic post-conflict situation, the international community is often called upon to replace the state as service provider ${ }^{\text {? }}$.

With their health projects, ECHO and its partners are attempting to cover health needs that are exacerbated by war (epidemics, malnutrition) and basic health needs that are emerging because of the complete breakdown of the health system. What is still lacking are preventive activities that, combined with nutrition and food security interventions, are liable to have greater impact on the health of the affected population than an extension of the coverage of health care, which risks becoming substandard. DRC is too vast a country for any single donor to cover all needs. The decision to concentrate activities in defined geographical areas certainly remains justified; however, the degree of poverty in the other zones may be just slightly lower with

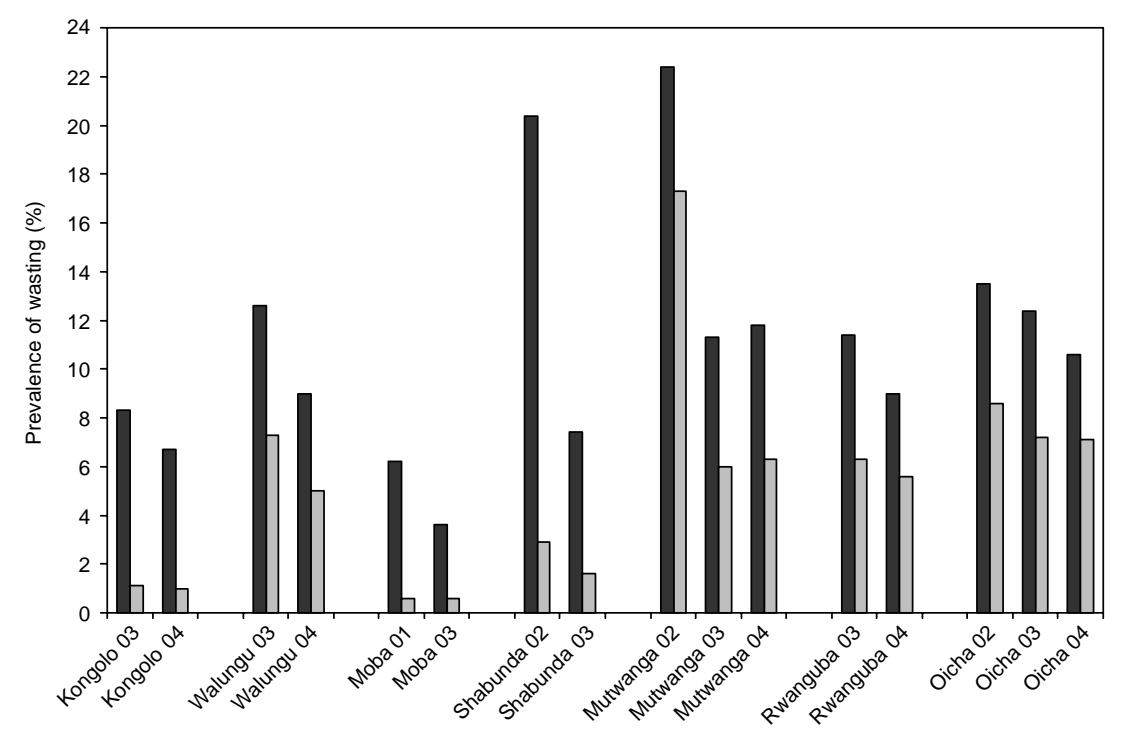

Fig. 2 Variation of prevalence of malnutrition ( $\boldsymbol{\square}$, global; $\square$, severe) in the areas covered by nutritional centres in different periods of activity (2001-2004). Global wasting defined as weight-for-height Z-score (WHZ) below -2 (i.e. below two standard deviations of the reference value); severe wasting as WHZ below -3 (i.e. below three standard deviations of the reference value); reference data from the National Center for Health Statistics ${ }^{8}$ 


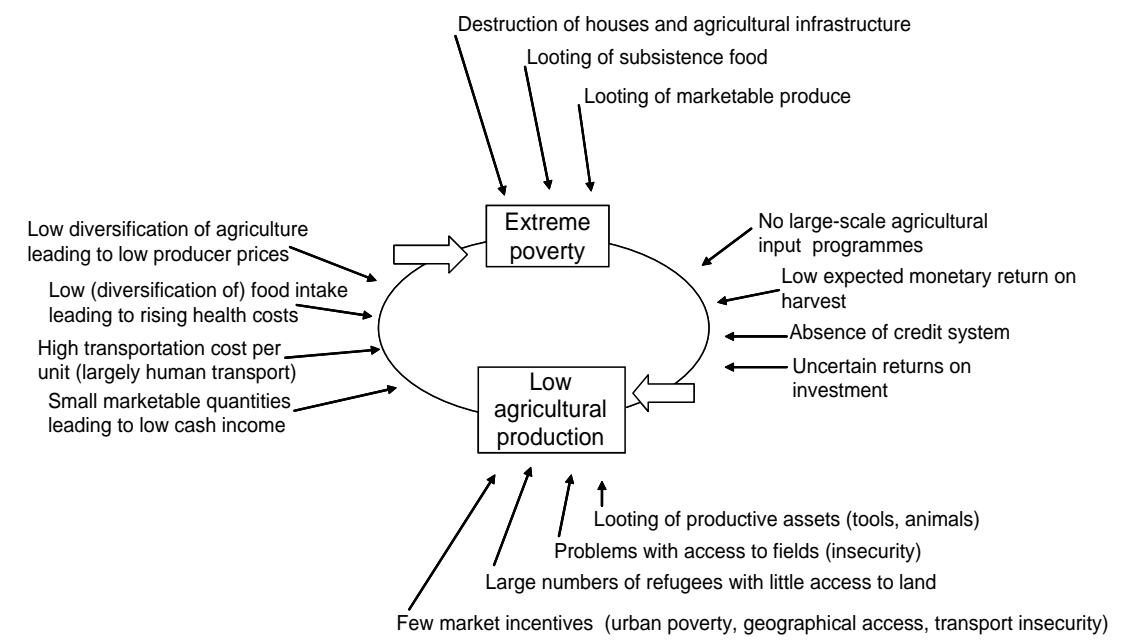

Fig. 3 A conceptual framework of the circular cause-and-effect relationship between poverty and agricultural production and contributing factors in Democratic Republic of Congo

the health system not performing at acceptable levels there either. The debate on health costs remains open. No value of flat fee can be proposed that would be appropriate for the whole target zone, considering the income differences and the different levels of poverty. On the other hand, health centres that charge only nominal fees reported a relevant portion of 'false' patients and misuses. ECHO is currently spending \$US 2.64 per person per year in the health zones covered by its partners. In contrast, a World Bank estimate pitches the cost of delivery of basic health services at \$US 12 per person per year ${ }^{10}$, and a more recent opinion of the World Health Organization is that below \$US 10 per person per year no equitable nor effective health care can be realistically provided ${ }^{11}$. In reality, donors tend to spend less than these recommendations, even in development settings: in Afghanistan, where health is currently being contracted out to non-governmental organisations, the Basic Package of Health Services is priced at \$US 4.55 per person per year ${ }^{11}$. Actually, in DRC, with the current level of funding, it is impossible to provide a full package of basic health services to the affected populations even though the implemented programmes have generally improved access to health care at the level of health centres.

Despite the large numbers of interventions the nutritional status of children remains drastically compromised, as demonstrated by Knowledge, Attitude and Practices survey data ${ }^{12}$ : stunting prevalence ranged from 32 and 59\% in the different provinces; wasting varied from 6 to $11 \%$; and oedema was still present in more than 3\% of children, reaching $14 \%$ in south Kivu. According to international references ${ }^{8}$, the public health level of attention of these indicators ranges from high (more than $40 \%$ of children stunted) to alarming (more than 10\% of children wasted). Reduction of malnutrition in project areas was often demonstrated, at least in the short term, even though the context did not permit a consolidation of the results. In NCs visited in our study, the adult admission rate differed greatly in the different intervention areas and interpretation of this finding is difficult without knowing the prevalence of malnutrition in this age group. Probably, the combination of IP policy and different levels of adult malnutrition in the activity zones was responsible for these large differences. Adults' admission to NCs was an important discussion issue between ECHO and IPs, with the donor more oriented towards a paediatric approach for the treatment of severe malnutrition. It could be useful to remember that the priority to protect the most vulnerable (children) may be the best approach in a situation of acute emergency, whereas it cannot be the optimal solution under conditions in which the main objectives are to recover agricultural production and reestablish a virtuous loop between well-being and productivity. In fact, adult malnutrition causes a significant reduction of working and functional capacity that represents a severe obstacle for a population aiming to escape the loop of poverty which links malnutrition, morbidity, low productivity and lack of foods. The decision to give priority to feeding the most vulnerable (children) or the most productive (adults) is an unsolvable dilemma. It should be also be pointed out that, even if the treatment of children is the primary focus of NCs, the additional cost for treating other age groups is, however, minimal.

The classical approach of management of acute malnutrition has been very successful in terms of clinical outcomes. However, although demonstrating a reduction of malnutrition in project areas, the impact of nutritional programmes has coverage limitations; in fact, a countrywide improvement of children's nutritional status was not achieved. It should be pointed out that this type of intervention is mainly aimed at solving the most critical situations, decreasing morbidity and mortality rather than reducing the prevalence of malnutrition at country 
level. There is increasing consent in the literature ${ }^{13,14}$ concerning the opportunity of evolving NCs into community-based therapeutic care (CTC), in which the approach of $100 \%$ inpatient therapeutic feeding should evolve into a partial outpatient model. This could increase family involvement and reduce the absence of mothers from the family, an important risk factor for other young siblings that are exposed to the same environment.

The conclusive idea of the evaluators on the future of relief projects in DRC is that the current targeted short-term actions should evolve towards 'integrated basic needs projects', implemented by one partner or a consortium of partners. For example, integrated health (with malaria and HIV prevention components), nutrition and food security projects should be considered a standard public health intervention strategy. The current situation of 'neither war nor peace' in Congo may last for years, as demonstrated by the conflict in December 2004 during the operations to disarm armed rebel Rwandan groups in eastern Congo ${ }^{15}$. In this context it is crucial that humanitarian actions be implemented in closer coordination with instruments of long-term agency. In fact, the distinction between 'emergency' and 'pre-development' is small, artificial and probably only academic. There is the need to fill the gap between pure emergency and development actions with, at least, mid-term programming cycles. Acute disasters attract international media and political attention - and often funds to support a response ${ }^{16}$. But media attention on specific major crises often results in other less publicised areas being overlooked in terms of advocacy and funding. The protracted complex emergency in DRC is one of these scenarios, being a long-term forgotten crisis that is still characterised by short-term funding and longterm needs.

\section{Acknowledgements}

Funding: The evaluation was financed by and carried out at the request of the European Commission Service (contract $\mathrm{ECHO} / \mathrm{EVA} / 210 / 2004 / 01207$ ). Its cost accounted for $0.12 \%$ of the $2002-2004$ ECHO assistance budget to DRC. The sponsor of the evaluation had no role in evaluation design, data collection, data analysis, data interpretation or in the decision to submit the paper for publication. The corresponding author had full access to all the data in the study and had final responsibility for the decision to submit for publication.

Disclaimer: The comments and conclusions contained in this paper reflect the opinions of the authors only and do not necessarily reflect those of the Commission Service, nor do they represent any official view of the ECHO.

Thanks: The authors express their gratitude to all those - partners, beneficiaries, affected population and external actors - who kindly gave their time for their contribution.
Especially appreciated was the highly effective logistical support of ECHO's Technical Assistants during the fieldwork, who achieved the near impossible in the DRC context.

\section{References}

1 International Red Cross (IRC). Mortality in the Democratic Republic of Congo: Results of a Nation-wide Survey. New York: IRC, 2003.

2 Carment D. Assessing state failure: implications for theory and policy. Third World Quarterly 2003; 24: 407-27.

3 European Commission Humanitarian Office (ECHO). Global Index for Humanitarian Needs Assessment (GINA). Brussels: ECHO, 2004. Also available at http://europa.eu. int/comm/echo/pdf_files/strategic_methodologies/glob_ needs_ass_2004_en.pdf

4 European Commission Humanitarian Office (ECHO). The Humanitarian Crisis in the Democratic Republic of Congo, ECHO's Longstanding Commitment. Brussels: ECHO, 2004. Also available at http://europa.eu.int/comm/echo/field/drc/ background_en.htm

5 The Sphere Humanitarian Charter and Minimum Standards in Disaster Response. Geneva: The Sphere Project, 2004. Also available at http://www.sphereproject.org

6 Programme National de Nutrition, Save the Children, Action Against Hunger, World Food Programme, United Nations Children's Development Fund. Protocole Nationale de Prise en Charge de la Malnutrion Aigue, Kinshasa, November 2002.

7 World Health Organization (WHO). Management of Severe Malnutrition: A Manual for Physicians and Other Senior Health Workers. Geneva: WHO, 1999.

8 World Health Organization (WHO). Physical Status: The Use and Interpretation of Anthropometry. WHO Technical Report Series No. 854. Geneva: WHO, 1995.

9 Bunde-Birouste A, Eisenbruch M, Grove N, Humphrey M, Silove D, Waller E. et al. Health and peace-building: securing the future. The University of New South Wales Health and Conflict Project and the School of Public Health and Community Medicine, Sydney, Australia, 2004.

10 World Bank. World Development Report: Investing in Health. New York: World Bank/Oxford University Press, 1993.

11 Pavignani E, Colombo A. Providing Health Services in Countries Disrupted by Civil Wars. A Comparative Analysis of Mozambique and Angola 1975-2000. Geneva: World Health Organization, 2001.

12 Programme National de Nutrition (ProNaNut)/United Nations Children's Fund (UNICEF). Knowledge Attitude and Practices on Prevention of Malnutrition: National Survey. Kinshasa: ProNaNut/UNICEF, 2003.

13 Collins S, Sadler K. Outpatient care for severely malnourished children in emergency relief programmes: a retrospective cohort study. Lancet 2002; 360: 1824-30.

14 Collins S. Changing the way we address severe malnutrition during famine. Lancet 2001; 358: 498-501.

15 Relief Web, Human Rights Watch. D.R. Congo: Civilians at Risk During Disarmament [online], 2004. Available at http:// www.reliefweb.int/w/rwb.nsf/6686f45896f15dbc852567ae0 0530132/5f4298319fb4c19b49256f790008706e?OpenDocument. Accessed 29 December 2004.

16 Sondrop E, Zwi A. Complex political emergencies we can learn from previous crisis. British Medical Journal 2002; 324: $310-1$ 